\title{
Parental desire and fertility preservation in assigned male at birth transgender people living in Belgium
}

\author{
Justine Defreyne ${ }^{a} \mathbb{D}$, Judith Van Schuylenbergh ${ }^{b}$, Joz Motmans ${ }^{b}$ (D) Kelly Tilleman ${ }^{c}$ and Guy T'Sjoen ${ }^{b}$ \\ ${ }^{a}$ Department of Endocrinology, Ghent University Hospital, Ghent, Belgium; ${ }^{b}$ Center for Sexology and Gender, Department of \\ Endocrinology, Ghent University Hospital, Ghent, Belgium; 'Department for Reproductive Medicine, Ghent University Hospital, \\ Ghent, Belgium
}

\begin{abstract}
Introduction: Transgender people who chose to proceed with gender affirming hormonal and/or surgical therapy, may face reduced options for fulfilling their parental desire in the future. The ideas and concerns of adult transgender people regarding fertility preservation and parental desire have never been reported in a large, non-clinical sample of assigned male at birth (AMAB) transgender people.

Methods: A web-based survey on fertility and parenthood in (binary and non-binary) transgender people was conducted in Belgium. AMAB people were selected for this analysis.

Results: We included 254 AMAB persons, of which 196 (77.2\%) self-identified as transgender women (TW), 14 (5.5\%) as cross-dressers and 44 (17.3\%) as gender non-binary (GNB) people. Fifty-five $(21.6 \%)$ respondents had a current/future parental desire, parental desire was already fulfilled in 81 (31.9\%) and not present in 57 people (22.4\%) (other: 19.2\%). TW were more likely to express a parental desire, compared to GNB people and cross-dressers $(P=0.004)$. In total, 196 AMAB people previously sought medical assistance, of which 30 $(15.3 \%)$ considered the loss of fertility due to the transitioning process undesirable. The majority (68.2\%) did not want fertility preservation (FP). Fourteen people $(9.8 \%)$ had proceeded with FP. The main reasons not to proceed with FP included not feeling the need (70; $68.0 \%$ ), not desiring a genetic link with (future) child(ren) $(20 ; 19.4 \%)$ and having to postpone hormone treatment $(15 ; 14.6 \%)$. TW were more likely to have a parental desire and to have cryopreserved or to consider cryopreserving gametes, compared to GNB people.

Conclusion: Parental desire and FP use were lower in the current non-clinical sample than in previous research on clinical samples. This can possibly be explained by the barriers transgender people face when considering fertility options, including postponing hormone therapy. Also, GNB persons have different needs for gender affirming treatment and FP.
\end{abstract}

\section{KEYWORDS}

cryopreservation; fertility; gender non-binary; parental desire; reproductive technologies; transgender

\section{Introduction}

Transgender people may report discomfort resulting from a discrepancy between the birth-assigned and their desired gender, often referred to as gender dysphoria. In order to alleviate gender dysphoria, some transgender people search for gender affirming care. Options for transition in transgender people include social, psychological and medical aspects (including gender affirming hormonal therapy and surgery). Gender affirming care has greatly evolved over time, also with improved surgical techniques. As gender affirming hormonal and surgical care has been shown to reduce or even resolve feelings of gender dysphoria in transgender people (Ainsworth \& Spiegel, 2010; De Cuypere et al., 2006; Fisher et al., 2014, 2016; Gómez-Gil et al., 2012; GorinLazard et al., 2012; Murad et al., 2010; Newfield, Hart, Dibble, \& Kohler, 2006; Rakic, Starcevic, Maric, \& Kelin, 1996; Smith, Van Goozen, Kuiper, \& Cohen-Kettenis, 2005; Weyers et al., 2009; Wierckx et al., 2011), gender affirming care should be accessible to all transgender people in need (Defreyne, Motmans, \& T'Sjoen, 2017).

If transgender people wish to proceed with gender affirming hormonal therapy, they can choose (according to their gender identity) between estrogen (plus anti-androgen) or 
testosterone therapy. In Europe, estrogens can be administered orally or transdermally and can be associated with anti-androgen therapy, when feminization is desired. In transgender adolescents, $\mathrm{GnRH}$ agonists can be used to suppress pubertal development (Gorton \& Erickson-Schroth, 2017). Although recent survey data in Belgium showed that roughly one third of the population of transgender people feel comfortable in their gender identity without gender affirming hormonal therapy and/or surgery (Motmans, Wyverkens, \& Defreyne, 2018), many transgender people seeking gender affirming treatment also prefer gender affirming surgery in order to alleviate their gender dysphoria(Motmans et al., 2018). In transgender people who were assigned male at birth (AMAB), options for gender affirming surgery include (but are not limited to) breast augmentation, orchiectomy, vaginoplasty and facial feminization surgery (Coleman et al., 2012). In Belgium, it was previously required to have gonadectomy performed in order to be able to change one's birth certificate sex. As of 2018, a new law was implemented for legal gender recognition without any medical criteria, but based solely on self-declaration and limited to binary gender (female or male) options. At the time of the data collection, this law was not yet implemented.

Gonadectomy in transgender people leads to an irreversible loss of natural reproductive capacity. Transgender people generally access reproductive medicine for two reasons: for fertility preservation (FP) prior to/during the transition process and to become parents. Even after gonadectomy, it remains possible for transgender people to have genetically related children if gametes or embryos have been cryopreserved beforehand. However, the preservation of gametes implicates an annual cost, financed by the patient (as this is not reimbursed in Belgium). Fertility options in transgender people are discussed elsewhere (De Roo, Tilleman, T'Sjoen, \& De Sutter, 2016; Mattawanon, Spencer, Schirmer, \& Tangpricha, 2018)

Although there are many options for FP in transgender people, many still consider fertility the price to pay for transition (T'Sjoen, Van Caenegem, \& Wierckx, 2013). The current literature shows low FP use in clinical samples of transgender people $(12.5 \%-15 \%$ in adults, $2.8 \%$ in adolescents) in Belgium as well as the USA (Motmans, T'Sjoen, \& Meier, 2011; Nahata, Tishelman, Caltabellotta, \& Quinn, 2017; Wierckx, Stuyver, et al., 2012). The WPATH SOC 7 (Coleman et al., 2012) encourages health care professionals to discuss reproductive options before initiating treatment that may reduce fertility. De Sutter et al. (De Sutter, Kira, Verschoor, \& Hotimsky, 2002) reported a parental desire in half of the transgender women in their sample. Therefore, we believe it is important for health care providers to get acquainted with the fertility needs of (AMAB) transgender people and to be able to discuss reproductive options in each stage of the gender affirming process, including giving information about the impact of gender affirming hormonal therapy on fertility (Kyweluk, Sajwani, \& Chen, 2018).

There are options for transgender care (mental health care, gender affirming hormones and surgical care) throughout Belgium, and gender affirming hormone care as well as certain surgical procedures (gonadectomy, mastectomy, genital surgery) are partly reimbursed, which is not the case for other (surgical) interventions such as facial feminization surgery (FFS), breast augmentation or epilation. However, a 2018 report by the Federal Institute for the equality of women and men (Motmans et al., 2018) described healthcare for transgender people in Belgium as problematic. This was mainly due to the large difference in availability of care between the regions, with the northern Flemish Region offering more self-help groups and more care providers and services than the Walloon Region of Belgium. In addition, approximately $10 \%$ of the respondents considered the waiting times for gender affirming care too long (Motmans et al., 2018). The study also revealed that transgender men and gender non-binary persons are often confronted with a lack of information and support in healthcare. FP services are available to transgender people in Belgium, although the cost for freezing and storing of gametes is not reimbursed and can add up to 1000-2000 euro, which may lead to transgender people not contacting FP services.

The present study assesses parental desire and ideas on FP and the use of assisted reproductive 
services in a large population based sample of AMAB transgender people.

\section{Methods}

From May 4th until June 30th 2017, an online anonymous survey mapping the situation of transgender people in Belgium was conducted, in Dutch, French and English. The study was ordered by the federal government, and the questionnaires can be found in the report 'Being transgender in Belgium - Ten years later' (Motmans et al., 2018). All people who were at least 16 years old, were living in Belgium during the last 24 months, and who self-identified as being transgender (including gender variant, gender non-binary, gender fluid, cross-dressers, etc.) were invited to participate. Participants were recruited via civil society organizations, via specific groups working with lesbian, gay, bisexual, transgender and queer (LGBTQ) people, through networks of transgender care providers and through an advertisement in an LGBTQ magazine. Survey invitations were also distributed digitally through listservs and social media and flyers and posters were distributed by post and at the annual LGBT pride in Brussels. A press release generated media attention and led to news articles in regular journals and newspapers. Pen and paper version were made available through local transgender organizations. Halfway through the data collection period, the collected data was analyzed to determine which segments of the transgender group were underrepresented, which prompted the researchers to make additional efforts to reach French-speaking transgender people.

The fertility and parental desire questionnaire was designed by the Ghent University Hospital Center for Sexology and Gender together with the Ghent University Hospital Center for Reproductive Medicine. Three main topics were assessed in the questionnaire: parental desire, loss of fertility and use of and barriers to FP. All procedures performed in studies involving human participants were in accordance with the ethical standards of the institutional and/or national research committee and with the 1964 Helsinki declaration and its later amendments or comparable ethical standards. Ethical approval for this study was requested and obtained from the Ethics Committee at the Ghent University Hospital (EC 2017/0599). The questionnaire included single and multiple response questions. An informed consent was obtained through an online form.

Participants were asked to identify their birthassigned sex, their current legal gender, as well as their current gender identity (multiple answer options were possible). Subsequently, it was explained that for reasons of data analysis, the research team needed to be able to categorize participants in one of four possible identity groups, and participants were asked which identity group they currently felt they belonged to, and preferred to be included in. Answer options were (transgender) woman, (transgender) man, cross-dresser, genderqueer/agender/polygender/ gender-fluid/non-binary, or 'I don't know, I don't have a preference'. The latter group was recoded into one of the four chosen identity groups labels, based on answers on birth-assigned gender and current gender. For these analyses, we selected birth-assigned males only. The GNB group included all birth-assigned male people, who indicated that their gender identity was not concordant with their birth-assigned sex, but who did not fully identify as being a '(transgender) man' or '(transgender) woman'.

Data were analyzed using IBM SPSS 24.0 software. Data were verified for normal distribution using Shapiro-Wilk test. Differences between groups were analyzed by Kruskal-Wallis $\mathrm{H}$ test (for non-normally distributed data) and for categorical variables, Fisher's exact t test was used. When comparing two groups, data were analyzed using Mann-Whitney $U$ test. Multiple response questions were analyzed using the SPSS 'multiple response' feature. In the results section, sometimes data for significant results are only shown in the tables in order to enhance the readability of the manuscript.

All differences between identity groups were controlled for sexual preference, age, living area (Flanders, Wallonia or Brussels Capital Region), educational level (according to ISCED (UNESCO (2009), 1997), subdivided in low-medium and high educational level), self-reported financial 
stress in the household (Anderson, Mikuliç, Vermeylen, Lyly-Yrjanainen, \& Zigante, 2009), native language (Dutch, French, German, English, Turkish, Arabic, or open answer option) and different stages in the gender affirming process (which included for AMAB respondents: having contacted a health care professional, mental health assessment, gender affirming hormonal therapy and chest surgery, gonadectomy and vaginoplasty). Sexual preference was asked as a multiple response question, which included the options 'I am attracted to men only, to women only, to men and women, to transgender persons, I don't feel attracted to anyone, I don't consider gender important, I don't know, or other (open answer option)'. Only those parameters having a significant impact on the results are discussed.

\section{Results}

From May 4th until June 30th, 754 self-identified transgender people from Belgium completed the online survey. After data cleaning, 543 participants were included in the analysis. Reasons for exclusion were age younger than 16 years old, being cisgender, not signing the informed consent or not having lived in Belgium in the previous 24 months. In addition, we excluded participants who completed the questionnaire in less than 15 minutes, as it would have been impossible to answer the extensive questionnaire during this time slot. In total, 426 participants filled in the fertility portion of the questionnaire, of which 254 (59.6\%) AMAB (196; 77.2\% transgender women (TW), 14; 5.5\% cross-dressers and $44 ; 17.3 \%$ GNB people).

Characteristics of the study population are shown in Table 1 . The median age of the AMAB group was 43.0 years [31.0 - 53.0]. TW were younger than GNB and cross-dressers. In total, $196(77.2 \%)$ people previously contacted a health care professional; TW were more likely to do so compared to GNB people and cross-dressers. People who underwent gonadectomy had accessed health care earlier compared to people who did not (yet) undergo gonadectomy (6.0 [4.0 - 14.3] years after first contact with health care provider versus $3.0[2.0-8.0]$ years, $P<0.001)$ and were also older (46.0 [31.0 - 54.0] years old versus 39.0 [28.0 - 50.0] years old, $P=0.027$ ).

\section{Parental desire}

Fifty-four (22.5\%) respondents had a current or future parental desire. Parental desire was already fulfilled in $79(32.9 \%)$ and not present in 53 people $(22.1 \%)$ (Table 2). TW were more likely to have a current/future parental desire, compared to GNB people, but not to cross-dressers. People with a current/future parental desire were

Table 1. Characteristics of the AMAB study population.

\begin{tabular}{|c|c|c|c|c|c|c|}
\hline & & $\begin{array}{l}\text { Transgender } \\
\text { women (196) }\end{array}$ & $\begin{array}{c}\text { Gender non binary } \\
\text { people (44) }\end{array}$ & Cross-dressers (14) & Total (329) & $\begin{array}{c}\text { Differences } \\
\text { between groups }\end{array}$ \\
\hline \multicolumn{2}{|c|}{ Age (median) (years) [P25 - P75] } & $41.0[29.0-51.0]$ & $47.5[35.3-56.0]$ & $50.5[46.0-56.5]$ & $43.0[31.0-53.0]$ & $P=0.003^{*}$ \\
\hline Sexually & Men & $38(19.4 \%)$ & $10(22.7 \%)$ & $2(14.3 \%)$ & $50(19.7 \%)$ & $P=0.763$ \\
\hline \multirow[t]{7}{*}{ attracted to } & Women & $78(39.8 \%)$ & $19(43.2 \%)$ & $7(50.0 \%)$ & $104(40.9 \%)$ & $P=0.701$ \\
\hline & Both & $65(33.2 \%)$ & $20(45.5 \%)$ & $3(21.4 \%)$ & $88(34.6 \%)$ & $P=0.190$ \\
\hline & Transgender people & $50(25.5 \%)$ & $15(34.1 \%)$ & $8(57.1 \%)$ & $73(28.7 \%)$ & $P=0.035$ \\
\hline & $\begin{array}{l}\text { I don't think gender } \\
\text { is important }\end{array}$ & $40(20.4 \%)$ & $9(20.5 \%)$ & 0 & 49 (19.3\%) & $P=0.170$ \\
\hline & No one & $17(8.7 \%)$ & $2(4.5 \%)$ & $1(7.1 \%)$ & $20(7.9 \%)$ & $P=0.168$ \\
\hline & I don't know & $18(9.2 \%)$ & $1(2.3 \%)$ & $1(7.1 \%)$ & $20(7.9 \%)$ & $P=0.311$ \\
\hline & Other & $25(12.8 \%)$ & $7(15.9 \%)$ & $1(7.1 \%)$ & $33(13.0 \%)$ & $P=0.774$ \\
\hline \multirow[t]{2}{*}{ Educational level } & Low - Medium & $104(53.1 \%)$ & $18(40.9 \%)$ & $5(35.7 \%)$ & $127(50.0 \%)$ & $P=0.193$ \\
\hline & High & $92(46.9 \%)$ & $26(59.1 \%)$ & $9(64.3 \%)$ & $127(50.0 \%)$ & \\
\hline \multicolumn{2}{|c|}{ Household under economical stress ( $\mathrm{n}$ yes) } & $66(33.7 \%)$ & $14(31.8 \%)$ & 0 & $80(31.5 \%)$ & $P=0.023^{*}$ \\
\hline \multirow[t]{3}{*}{ Region } & Brussels Capital Region & $17(8.7 \%)$ & $5(11.4 \%)$ & / & $22(8.7 \%)$ & $P=0.274$ \\
\hline & Flanders & $139(70.9 \%)$ & $32(72.7 \%)$ & $14(100.0 \%)$ & $185(72.8 \%)$ & \\
\hline & Wallonia & $35(17.9 \%)$ & $7(15.9 \%)$ & / & $42(16.5 \%)$ & \\
\hline \multirow{6}{*}{$\begin{array}{l}\text { Previously contact } \\
\text { Initiated gender } \\
\text { affirming therapy }\end{array}$} & a health care professional & $167(85.2 \%)$ & $23(52.3 \%)$ & $6(42.9 \%)$ & $196(77.2 \%)$ & $P<0.001^{*}$ \\
\hline & Mental health & $167(85.2 \%)$ & $11(25.0 \%)$ & $1(7.1 \%)$ & $179(70.5 \%)$ & $P<0.001^{*}$ \\
\hline & $\begin{array}{l}\text { Gender } \\
\text { affirming hormones }\end{array}$ & $134(68.4 \%)$ & $9(20.5 \%)$ & 0 & $143(56.3 \%)$ & $P<0.001^{*}$ \\
\hline & Breast augmentation & $44(22.4 \%)$ & $2(4.5 \%)$ & 0 & $46(18.1 \%)$ & $P=0.149$ \\
\hline & Orchiectomy & $54(27.6 \%)$ & $1(2.3 \%)$ & 0 & $55(21.7 \%)$ & $P=0.010^{*}$ \\
\hline & Vaginoplasty & $50(25.5 \%)$ & $1(2.3 \%)$ & 0 & $51(20.1 \%)$ & $P=0.017^{*}$ \\
\hline
\end{tabular}






younger $(31.0[25.0-40.0])$ compared to people without (46.0 [34.0 - 53.0], $P<0.001)$. In addition, people who were sexually attracted to women less frequently desired to have children, compared to those not attracted to women.

Subsequently, participants were asked which main barriers they encountered or feared to encounter when wanting to fulfill their parental desire (multiple responses were possible). Most often encountered were fear of their child being discriminated due to their parent(s) being transgender $(33,38.4 \%$ of cases), and the assumed difficulties with the adoption procedure for genetically non-related children $(32,37.2 \%$ of cases). These frequencies were comparable in TW, GNB persons and cross-dressers $(\mathrm{P}=\mathrm{NS})$ (Figure 1).

\section{Loss of fertility}

Loss of fertility after gonadectomy was considered undesirable by 43 people (16.9\%), 119 (46.9\%) did not, 39 (15.4\%) had no opinion and 53 $(20.9 \%)$ felt this question was not applicable to them. TW were more likely not to consider the loss of fertility as undesirable $(103 ; 52.6 \%)$ compared to GNB people $(12 ; 27.3 \%, P<0.001)$. More participants who had a current/future parental desire considered the loss of fertility as undesirable $(17 ; 31.5 \%)$, compared to those without $(23,13.6 \%, P<0.001)$. Reasons for considering the loss of fertility as undesirable (multiple response) are shown in Figure 2.

Participants were asked if they would proceed with gonadectomy if it were not a requirement for legal gender affirmation. In total, 100 respondents $(39.4 \%)$ would still undergo gonadectomy, one fifth $(50 ; 19.7 \%)$ would not, 37 (14.6\%) did not know, this question was not applicable to 21 people $(8.3 \%)$, and 46 people (18.1\%) did not respond to this question (Table 3). TW were more likely to proceed with gonadectomy if it were not a requirement for legal gender affirmation, compared to GNB people and cross-dressers. Participants who already contacted a health care professional regarding their gender dysphoria, were more likely to indicate that they would still undergo orchiectomy compared to those who had not. 


\section{Barriers to fulfilling the parental desire}

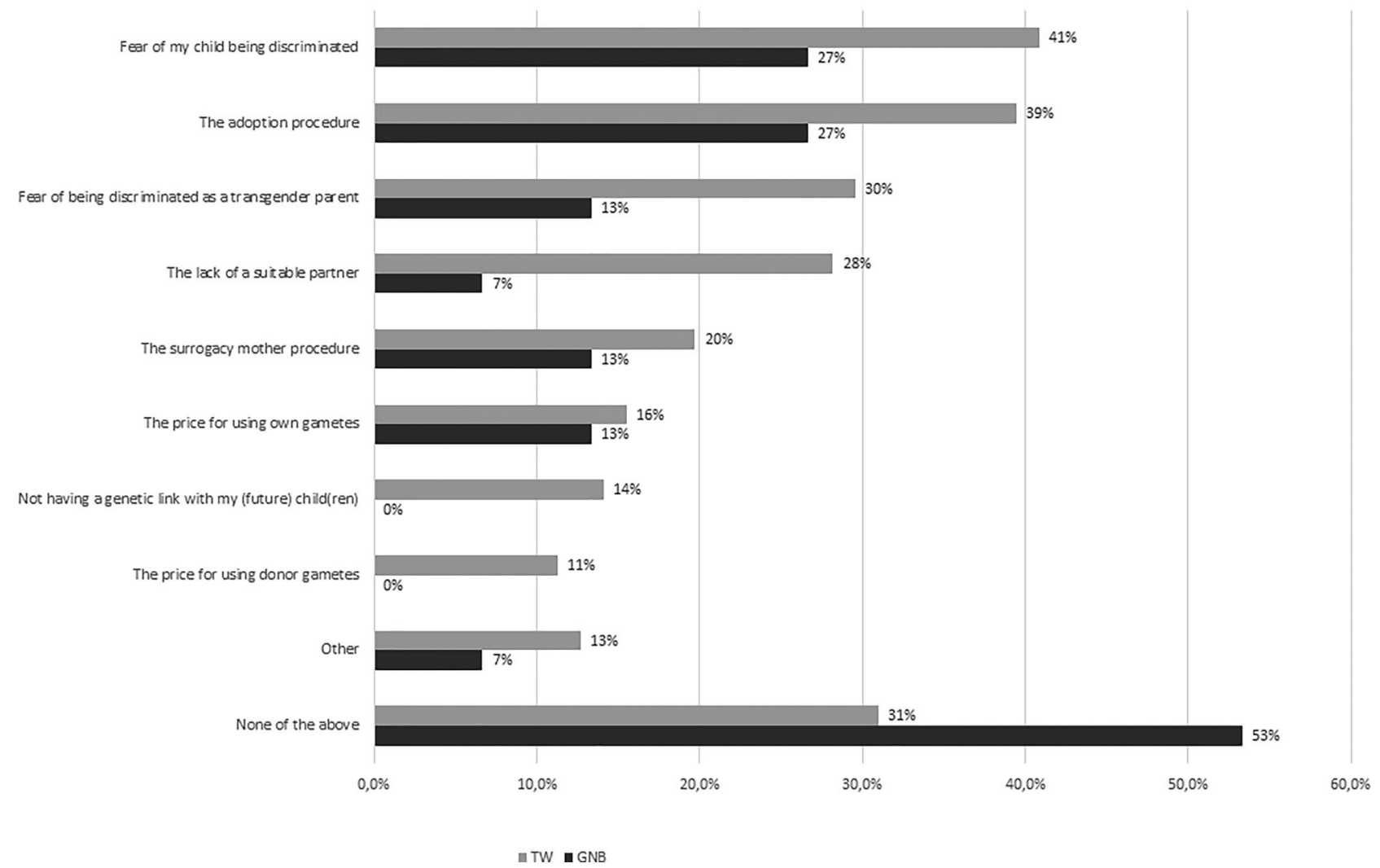

Figure 1. Barriers to fulfilling parental desire in $A M A B$ transgender people ( $T W=$ transgender women, $G N B=$ gender non binary, multiple response). Participants who had proceeded with or considered fertility preservation were asked how they would like to proceed if they wanted to have genetically related children. They could choose multiple answers from a list of possible reasons, including an open 'other' category. The 'other' category included people who felt they were too old to have children ( $\mathrm{n}=4$ ), to whom the question was no longer applicable $(n=3)$, did not desire children $(n=1)$ or were infertile $(n=1)$. None of the crossdressers in the AMAB study population indicated that they had gametes frozen or considered doing so in the future, therefore this group was not included.

Main reasons for not undergoing gonadectomy (multiple response, \% of cases) included not needing this $(35 ; 70.0 \%)$, and not wanting unnecessary surgery $(37 ; 74.0 \%)$. Only a minority did not want to lose their fertility $(8 ; 16.0 \%)$ or indicated other reasons $(4 ; 8.0 \%)$, including "I want to preserve sexual function" or "gonadectomy as a requirement for legal gender affirmation is inhumane".

\section{Fertility preservation}

\section{Information}

In total, 126 respondents (50.6\%, 5 missing) stated they did not receive information on $\mathrm{FP}$, of which 9 (3.6\%) indicated that they wanted information, although they had not received it. Half of the respondents $(123 ; 49.4 \%)$ had received information regarding fertility options: $26.9 \%$ from health care workers, $8.8 \%$ from an LGBTQ organization and $13.7 \%$ did their own research or asked friends/acquaintances.

People who had received information were younger compared to those who did not (36.0 [27.0 - 51.0] versus 46.5 [35.8 - 53.0], $P<0.001)$. GNB people $(11,26.8 \%)$ and cross-dressers (1; $7.7 \%)$ were less likely to receive information compared to TW $(111,56.9 \%)(P<0.001)$. Respondents who previously sought medical assistance were more likely to have received information, compared to those who did not $(111 ; 56.6 \%$ versus $12 ; 22.6 \%$, $P<0.001)$. In addition, respondents who initiated mental health care and gender affirming hormonal therapy were more likely to have received information (mental health care: 108; 60.3\% versus 11; $26.2 \%, P<0.001$, hormonal therapy: $89 ; 62.2 \%$ versus $29 ; 39.7 \%, P=0.002$ ). 


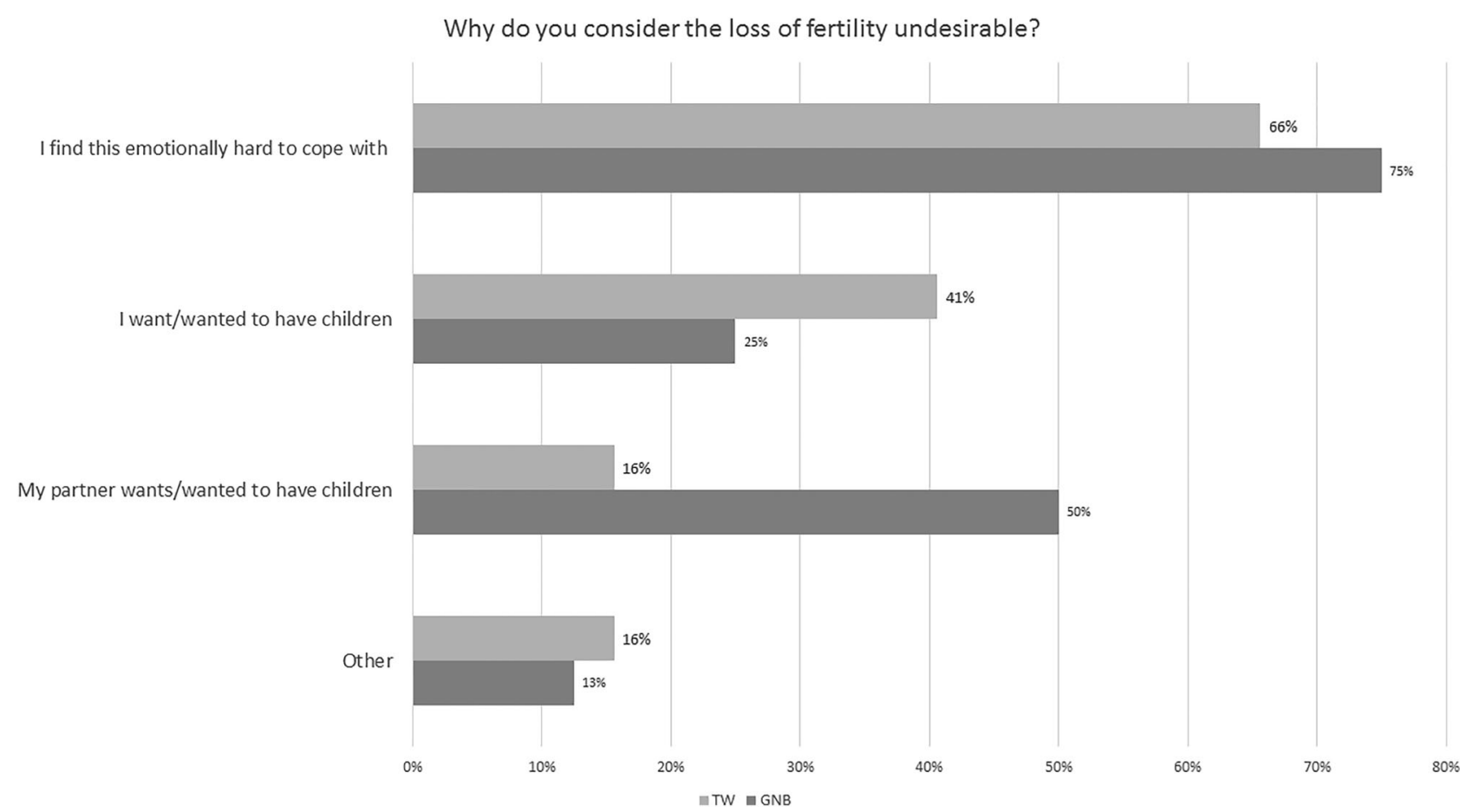

Figure 2. Reasons for considering the loss of fertility as undesirable in $A M A B$ transgender people (TW= transgender women, $\mathrm{GNB}=$ gender non binary, multiple response). Cross-dressers were not included, as only 1 person out of this group answered this question.

Table 3. Responses to the question 'Would you proceed with gonadectomy if it were not a requirement for legal gender affirmation?', subdivided by gender identity groups, groups with/without parental desire, having accessed transgender care, people who underwent psychological evaluation, who initiated gender affirming hormones, who underwent orchiectomy, groups based upon educational level, geographical region and mother language. This question was not answered by 46 people (18.1\%). Percentages are based on the total number of participants who answered this question. Differences between groups were calculated by Fisher's exact $t$ test. Other factors that did not significantly affect the responses among the study population (sexual attraction $(P$-values range $0.182-0.779$ ), parental desire: $P=0.187$, educational level: $P=0.604$, economic status: $P=0.178$ ) were not included.

\begin{tabular}{|c|c|c|c|c|c|c|}
\hline \multicolumn{2}{|c|}{ Would you proceed with gonadectomy? } & \multirow{2}{*}{$\frac{\text { Yes }}{100(48.1 \%)}$} & \multirow{2}{*}{$\frac{\text { No }}{50(24.0 \%)}$} & \multirow{2}{*}{$\frac{\text { I don't know }}{37(17.8 \%)}$} & \multirow{2}{*}{$\frac{\text { Not applicable }}{21(10.1 \%)}$} & \multirow[t]{2}{*}{$\begin{array}{c}\text { Differences } \\
\text { between groups }\end{array}$} \\
\hline Total & & & & & & \\
\hline \multirow[t]{3}{*}{ Gender identity } & Transgender women & $94(60.3 \%)$ & $27(17.3 \%)$ & $27(17.3 \%)$ & $8(5.1 \%)$ & $P<0.001$ \\
\hline & Gender non binary & $4(9.8 \%)$ & $22(53.7 \%)$ & $8(19.5 \%)$ & $7(17.1 \%)$ & \\
\hline & Cross-dressers & $2(18.2 \%)$ & $1(9.1 \%)$ & $2(18.2 \%)$ & $6(54.2 \%)$ & \\
\hline \multirow[t]{2}{*}{ Parental desire } & Yes & $25(58.1 \%)$ & $11(25.6 \%)$ & $5(11.6 \%)$ & $2(4.7 \%)$ & $P=0.187$ \\
\hline & No & $65(43.0 \%)$ & $37(24.5 \%)$ & $31(20.5 \%)$ & $18(11.9 \%)$ & \\
\hline \multirow[t]{2}{*}{ Accessed transgender care } & Yes & $84(54.2 \%)$ & $32(20.6 \%)$ & $29(18.7 \%)$ & $10(6.5 \%)$ & $P=0.001$ \\
\hline & No & $16(30.2 \%)$ & $18(34.0 \%)$ & $8(15.1 \%)$ & $11(20.8 \%)$ & \\
\hline \multirow[t]{2}{*}{ Psychological evaluation } & Yes & $85(60.7 \%)$ & $22(15.7 \%)$ & $24(17.1 \%)$ & $9(6.4 \%)$ & $P=0.005$ \\
\hline & No & $14(35.0 \%)$ & $16(40.0 \%)$ & $8(20.0 \%)$ & $2(5.0 \%)$ & \\
\hline \multirow[t]{2}{*}{ Gender affirming hormones } & Yes & $69(61.1 \%)$ & $22(19.5 \%)$ & $14(12.4 \%)$ & $8(7.1 \%)$ & $P<0.001$ \\
\hline & No & $27(42.9 \%)$ & $16(25.4 \%)$ & $17(27.0 \%)$ & $3(4.8 \%)$ & \\
\hline \multirow[t]{2}{*}{ Chest reconstructive surgery } & Yes & $22(71.0 \%)$ & $5(16.1 \%)$ & $2(6.5 \%)$ & $2(6.5 \%)$ & $P=0.168$ \\
\hline & No & $74(51.4 \%)$ & $33(22.9 \%)$ & $29(20.1 \%)$ & $8(5.6 \%)$ & \\
\hline \multirow[t]{2}{*}{ Underwent orchiectomy } & Yes & $32(84.2 \%)$ & $1(2.6 \%)$ & $2(5.3 \%)$ & $3(7.9 \%)$ & $P<0.001$ \\
\hline & No & $62(73.4 \%)$ & $37(27.4 \%)$ & $29(21.5 \%)$ & $7(5.2 \%)$ & \\
\hline \multirow[t]{2}{*}{ Underwent vaginoplasty } & Yes & $29(76.3 \%)$ & $1(2.6 \%)$ & $2(5.3 \%)$ & $6(15.8 \%)$ & $P<0.001$ \\
\hline & No & $67(48.6 \%)$ & $37(26.8 \%)$ & $29(21.0 \%)$ & $5(3.6 \%)$ & \\
\hline
\end{tabular}

\section{Fertility preservation rates}

Fifteen respondents $(8.7 \%, 82$ missing) had proceeded with FP, and $16(9.3 \%)$ considered doing this in the future (Table 4). Those who proceeded with FP or considered to do so in the future were on average younger, compared to those who did not (29.0 [22.0 - 35.0] and 27.0 [23.0 - 33.5] versus 40.0 [28.0 - 52.0], $P=0.002$. Respondents who had received information on fertility, visited a mental health professional, or initiated gender 
Table 4. Use of fertility preservation services in our study population, subdivided by groups based upon receiving information about fertility preservation, groups who underwent psychological evaluation, who initiated gender affirming hormones and groups based upon geographical region. Missing data were not included in this analysis (TW: \%, GNB: 5, 8.9\%). Differences between groups were calculated by Fisher's exact $t$ test. Other factors that did not significantly affect the use of fertility preservation services among the study population (gender identity groups: $P=0.362$, sexual attration ( $P$-values range $0.121-1.000$ ), parental desire: $P=0.325$, having accessed health care: $P=0.181$, underwent breast augmentation: $P=0.116$, orchiectomy: $P=0.084$ or vaginoplasty: $P=0.097$, economic status: $P=0.245$, educational level: $P=0.239$, mother tongue: $P=0.063$ ) were not included.

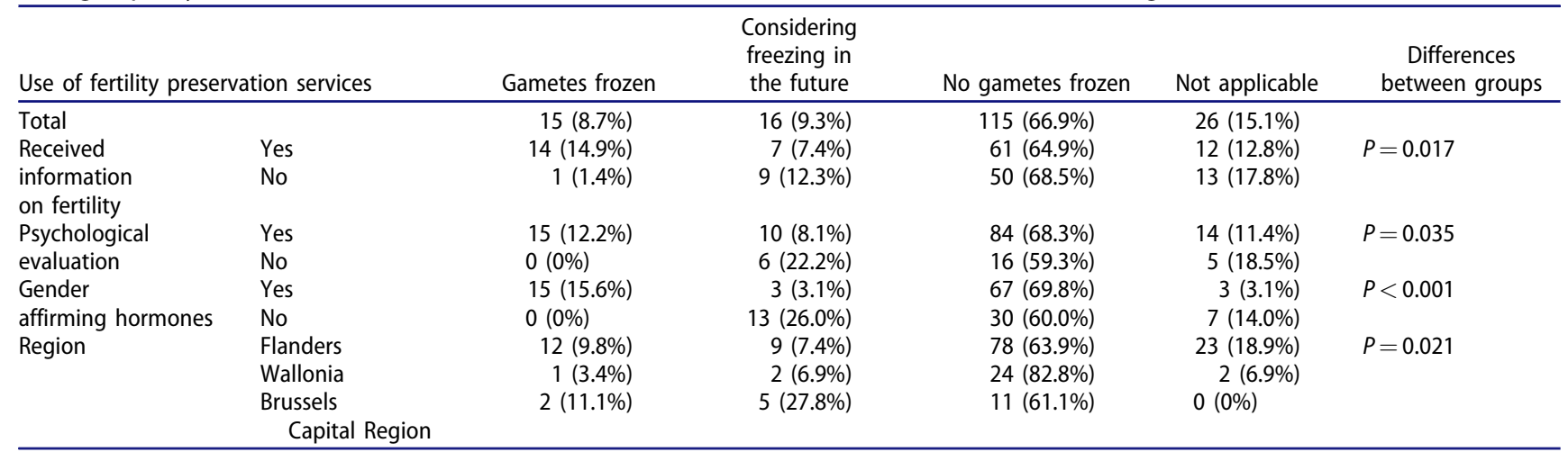



Figure 3. Reasons not to proceed with fertility preservation in $A M A B$ transgender people (TW=transgender women, $\mathrm{GNB}=$ gender non binary, multiple response). Participants who did not freeze gametes (yet) ( $\mathrm{n}=131$ ), were asked why they considered the loss of fertility as undesirable. They could choose multiple answers from a list of possible reasons, including an open 'other' category. The 'other' category mainly included people with whom this option was not discussed at the time of transitioning $(n=4)$, felt they were too old to freeze gametes $(n=2)$, already had children $(n=2)$ or did not want to fulfill the parental desire this way $(n=2)$. One person already underwent vasectomy before transitioning.

affirming hormones were more likely to have proceeded with FP, compared to those who did not.

Respondents who did proceed with FP (131, $76.2 \%)$ were asked what their reasons were (multiple response) (Figure 3). Most frequently reported were 'I don't feel the need for this' (68.0\% of the respondents), 'I don't think having a genetic link to my children is important' (19.4\% of the respondents), and 'I did not want to postpone gender affirming hormonal therapy' (14.6\% of the respondents). There appeared to be 
no significant difference in reasons not to preserve gametes between various gender identity groups $(\mathrm{P}=\mathrm{NS})$.

Respondents who considered FP in the future $(16,11.0 \%)$ were asked which barriers they feared to encounter (multiple response). Main barriers included having to interrupt/postpone gender affirming hormones (53.3\% of the respondents), the cost for freezing and storing (46.7\%) and having to masturbate to produce a sperm sample (26.7\%). These responses were not significantly different between gender identity groups $(P=N S)$.

We asked respondents who considered or had undertaken FP how they would like to proceed if they wanted to have genetically related children (multiple response). The majority preferred inseminating a female partner with their sperm cells $(15 ; 51.7 \%)$, or did not know this yet (12; $41.4 \%)$. These responses were not different between gender identity groups $(\mathrm{P}=\mathrm{NS})$.

\section{Discussion}

The right to found a family without discrimination based on sexual orientation or gender identity is stated in the Yogyakarta principles (principle 24) (O'Flaherty \& Fisher, 2008). The Yogyakarta principles were intended to serve as a universal guide to human rights which affirm binding international legal standards with which all States must ideally comply. The 29 principles insist that sexual and gender minorities should be guaranteed a range of basic rights. The Yogyakarta principles were revised 2017, when 10 additional principles were added (YP +10$)$ (Yogyakarta Principles, 2017). These additional principles were designed to protect people against violations on grounds of sexual orientation and gender identity and the recognition of the distinct and intersectional grounds of gender expression and sex characteristics.

Parental desire rates were lower in the current sample, compared to previous studies conducted in clinical (Auer et al., 2018; Wierckx, Van Caenegem, Pennings, et al., 2011) and non-clinical samples (De Sutter et al., 2002; Motmans, de Boilley, \& Debunne, 2009; Motmans et al., 2011), and also lower compared to non-transgender samples, e.g., a parental desire rate of $90 \%$ in a sample of the general US population aged 20-40 years old (Newport \& Wilke, 2013). Previous research among lesbian, gay, bisexual, transgender, and queer (LGBTQ) people hypothesized that a lack of support and encouragement by others when expressing their parental desires (Goldberg, Downing, \& Moyer, 2012) may lead to being more open to alternate means of parenthood, or to not having children at all (Nahata, Curci, \& Quinn, 2018; Russell, Galvin, Harper, \& Clayman, 2016).

In two earlier studies (Auer et al., 2018; De Sutter et al., 2002), half of the transgender respondents indicated preferring adoption, whereas the other half would prefer to have a genetically related child; $25 \%$ expressed a wish to receive a donor uterus to give birth to a child and only $10 \%$ considered insemination of a female partner with own sperm. In the present study, participants identified assumed difficulties within the adoption procedure as one of the main barriers to fulfilling their parental desire.

In line with earlier research (De Sutter et al., 2002), only a minority considered the loss of fertility due to gender affirming treatment as undesirable in the current study. This may indicate that the transgender people in our survey are more open to alternate means of parenthood, as previously reported by Auer et al. (Auer et al., 2018) and Riggs and Bartholomaeus (Riggs \& Bartholomaeus, 2018).

Until December 2017, gonadectomy was required in order to be able to change the legal gender marker in Belgium. In the current study, half of the respondents would still undergo orchiectomy if it were not necessary for legal gender affirmation. An earlier survey conducted in Belgium in the year 2010 also reported that $88 \%$ of the TW did not consider fertility loss a reason not to undergo gonadectomy (Motmans et al., 2011). These results reflect the need for transition related care in some of the transgender people in this sample, which may be of higher priority than the need for FP or the desire for genetically related children.

The number of people who proceeded with FP was lower in the current sample, compared to older studies in adult transgender people, stating that $51 \%$ would seriously consider FP if it would be possible (De Sutter et al., 2002) and 12.5\% - 
$15 \%$ of TW actually preserving gametes (Motmans et al., 2011; Wierckx, Stuyver, et al., 2012). However, our results are in line with more recent results from a clinical study by Auer et al. (Auer et al., 2018) and from a community-based study by Riggs et al. (Riggs \& Bartholomaeus, 2018) who reported that 9.6 and $7.0 \%$ of the TW had proceeded with $\mathrm{FP}$, respectively.

When comparing these numbers to nontransgender populations, e.g., $\mathrm{FP}$ rates of $49 \%$ in male cancer survivors with a mean age of 28 years old (Bann et al., 2015), it becomes apparent that FP use in transgender people remains low. However, people who proceeded with FP were often better informed about the available options. Financial issues were rarely reported as a major reason for not proceeding with FP. Also, a high number of people did not feel the need for FP $(68 \%)$. Based on our findings, our hypothesis that the transgender people in our survey are more open to alternate means of parenthood, including adoption, was supported (Auer et al., 2018). However, we should note that the current study included a non-clinical sample. Some of the participants may never wish for gender affirming hormone therapy and/or gonadectomy or may prefer other options for fulfilling their parental desire.

In the current sample, FP options are often discussed early in the gender affirmation process. Discussing FP options early should prevent transgender people from not proceeding with FP out of fear for delaying gender affirming hormone treatment and/or hysterectomy. However, a minority of the respondents stated that they did not proceed with FP because they did not want to postpone treatment with gender affirming hormones. Previous research on testicular function in orchiectomy specimens of AMAB transgender people shows conflicting results, with normal spermatogenesis in $0-48 \%$ of patients (Adeleye, Reid, Kao, Mok-Lin, \& Smith, 2019; Jiang et al., 2019; Jindarak et al., 2018; Leavy et al., 2017; Matoso et al., 2018; Schneider et al., 2015). One case report (Alford, Theisen, Kim, Bodie, \& Pariser, 2019) described sperm cryopreservation after 16 months of spironolactone therapy, which was stopped 2 months before sperm cryopreservation. A regimen with follitopin alfa and clomiphene citrate was necessary in order to proceed with sperm cryopreservation. However, none of these papers reported suppressed serum levels of testosterone. It is likely that effectively suppressing serum testosterone levels by anti-androgen therapy may result in suppressed spermatogenesis in the majority (if not all) AMAB transgender people, although further research is necessary. Therefore, we advise AMAB transgender people who consider FP, to cryopreserve gametes prior to initiating gender affirming hormone care.

Given the contradicting results of studies examining testicular tissue in TW, guidelines by the Endocrine Society (Hembree et al., 2017), the World Professional Association for Transgender Health (Coleman et al., 2012), and the American Society for Reproductive Medicine (Ethics Committee of the American Society for Reproductive Medicine, 2015) advise health care providers to address potential infertility risk and FP options with transgender people before starting treatment. In addition, it may be useful to provide information about options for fulfilling a parental desire in the general (non-clinical) transgender population, as one third of the respondents indicated they had not received this information. This may help transgender people to make an informed and individual decision on whether or not to proceed with FP or to explore other options for fulfilling a parental desire.

Although one fifth of the AMAB transgender population in the current sample had current/ future parenthood desires, FP rates are low. Main reasons for $\mathrm{AMAB}$ transgender persons foregoing FP techniques included having to interrupt or postpone gender affirming hormones, the cost for FP and having to masturbate to produce a sperm sample. These results are in line with the perception of barriers in adolescent transgender people (Brik et al., 2019; Kyweluk et al., 2018; Nahata et al., 2017). In addition, in Belgian regions where gender affirming care was less easily accessible (Brussels Capital Region and Wallonia), the number of people considering or proceeding with FP was lower compared to Flanders, which houses the largest center for transgender care in Belgium. Overcoming all barriers to FP (not only geographical) as well as barriers to other options for fulfilling a parental desire in transgender people (e.g., adoption) 
seems necessary. This could result in more people fulfilling their parental desire, if present.

This is the first large population-based survey combining questions on parental desire and FP which also included different gender identity groups, such as GNB people and cross-dressers. This study assesses the different needs of different identity groups, but also recognizes their diversity, by controlling for socio-demographic parameters and gender affirming treatment. It is however possible that smaller sample sizes within subgroups may have led to not rejecting a null hypothesis that is false (type II error). In addition, this study was conducted in Belgium. Our results may not be representative for other regions where the availability of options for gender affirming care and the legislation may differ from our setting. It is also possible that our sample is not representative for the entire transgender population in Belgium, as the survey was conducted online in Dutch, French and English. Transgender people without access to internet or with insufficient knowledge of these languages are not included in this sample.

\section{Conclusions}

As gender affirming care may reduce future parenthood options, it is important to enquire about reproductive wishes in those at risk for infertility caused by medical treatment and direct them to FP services, if needed. In the current sample of AMAB transgender people, the use of FP was low. We were able to identify the following barriers to $\mathrm{FP}$ in $\mathrm{AMAB}$ transgender people: having to interrupt or postpone gender affirming hormone treatment, the cost for FP and having to masturbate to produce a semen sample. In addition, people who had not received information on FP or who lived in a region where FP services were less easily available, were less likely to proceed with FP. It remains important to increase the availability of information about FP options for all transgender people of all ages, including those who did not visit a health care provider (yet) so that they can make an informed decision whether or not to proceed with FP. It is important to overcome barriers to and ensure access to FP services for all transgender people.
GNB people were often overlooked in previous research concerning parental desire and FP use, but awareness on the specific needs of this group increases. As $52 \%$ of GNB people in our study population had contacted a health care professional, we believe it is important also for health care workers to abandon the binary 'transgender men/transgender women' categories and acknowledge the fact that the transgender population is very diverse. Information sharing and decisions regarding FP use or other fertility options should preferentially be made early in the process, and without presumptions of the individual's wishes.

\section{Funding}

This work is supported by Fonds voor Wetenschappelijk Onderzoek (FWO) TBM T001816N. The data were collected as part of a study conducted with a federal research grant from the Institute of Equality between women and men.

\section{ORCID}

Justine Defreyne (D) http://orcid.org/0000-0002-6570-2340

Joz Motmans (D) http://orcid.org/0000-0001-7643-4153

\section{Conflict of interest}

The authors report no conflicts of interest.

\section{Ethical approval}

All procedures performed in studies involving human participants were in accordance with the ethical standards of the institutional and/or national research committee and with the 1964 Helsinki declaration and its later amendments or comparable ethical standards. Ethical approval for this study was requested and obtained from the Ethics Committee at the Ghent University Hospital (EC 2017/0599).

\section{References}

Adeleye, A. J., Reid, G., Kao, C. N., Mok-Lin, E., \& Smith, J. F. (2019). Semen parameters among transgender women with a history of hormonal treatment. Urology, (124), 136-141. doi:10.1016/j.urology.2018.10.005

Ainsworth, T. A., \& Spiegel, J. H. (2010). Quality of life of individuals with and without facial feminization surgery or gender reassignment surgery. Quality of Life Research, 19(7), 1019-1024. doi:10.1007/s11136-010-9668-7 
Alford, A. V., Theisen, K., Kim, N., Bodie, J., \& Pariser, J. (2019). Successful ejaculatory sperm cryopreservation after cessation of long-term estrogen therapy in a transgender female. Urology, pii: S0090-4295(19)30739-3. [Epub ahead of print]. doi:10.1016/j.urology.2019.08.021

Anderson, R., Mikuliç, B., Vermeylen, G., Lyly-Yrjanainen, M., \& Zigante, V. (2009). Second European quality of life survey-overview.

Auer, M. K., Fuss, J., Nieder, T. O., Briken, P., Biedermann, S. V., Stalla, G. K., ... Hildebrandt, T. (2018). Desire to have children among transgender people in germany: A cross-sectional multi-center study. The Journal of Sexual Medicine, 15(5), 757-767. doi:10.1016/j.jsxm.2018.03.083

Bann, C. M., Treiman, K., Squiers, L., Tzeng, J., Nutt, S., Arvey, S., ... Rechis, R. (2015). Cancer survivors' use of fertility preservation. Journal of Women's Health, 24(12), 1030-1037. doi:10.1089/jwh.2014.5160

Brik, T., Vrouenraets, L. J. J. J., Schagen, S. E. E., Meissner, A., de Vries, M. C., \& Hannema, S. E. (2019). Use of fertility preservation among a cohort of transgirls in the Netherlands. Journal of Adolescent Health, (64(5), 589-593. doi:10.1016/j.jadohealth.2018.11.008

Coleman, E., Bockting, W., Botzer, M., Cohen-Kettenis, P., DeCuypere, G., Feldman, J., ... Zucker, K. (2012). Standards of Care for the health of transsexual, transgender, and gender-nonconforming people. International Journal of Transgenderism, 13(4), 165-232. doi:10.1080/ 15532739.2011.700873

De Cuypere, G., Elaut, E., Heylens, G., Van Maele, G., Selvaggi, G., T’Sjoen, G., ... Monstrey, S. (2006). Longterm follow-up: Psychosocial outcome of Belgian transsexuals after sex reassignment surgery. Sexologies, 15(2), 126-133. doi:10.1016/j.sexol.2006.04.002

De Roo, C., Tilleman, K., T 'Sjoen, G., \& De Sutter, P. (2016). Fertility options in transgender people Fertility options in transgender people. International Review of Psychiatry, 28(1), 112-119. doi:10.3109/09540261.2015. 1084275

De Sutter, P., Kira, K., Verschoor, A., \& Hotimsky, A. (2002). The desire to have children and the preservation of fertility in transsexual women: A survey. International Journal of Transgenderism, 6(3), 3-97.

Defreyne, J., Motmans, J., \& T'Sjoen, G. (2017). Healthcare costs and quality of life outcomes following gender affirming surgery in trans men: A review. Expert Review of Pharmacoeconomics \& Outcomes Research, (17(6), 543-556. doi:10.1080/14737167.2017.1388164

Ethics Committee of the American Society for Reproductive Medicine. (2015). Access to fertility services by transgender persons: An ethics committee opinion. Fertility and Sterility, 104(5), 1111-1115.

Fisher, A. D., Castellini, G., Bandini, E., Casale, H., Fanni, E., Benni, L., ... Rellini, A. H. (2014). Cross-sex hormonal treatment and body uneasiness in individuals with gender dysphoria. The Journal of Sexual Medicine, 11(3), 709-719. doi:10.1111/jsm.12413
Fisher, A. D., Castellini, G., Ristori, J., Casale, H., Cassioli, E., Sensi, C., ... Maggi, M. (2016). Cross-Sex hormone treatment and psychobiological changes in transsexual persons: two-year follow-up data. The Journal of Clinical Endocrinology \& Metabolism, 101(11), 4260-4269. doi:10. 1210/jc.2016-1276

Goldberg, A. E., Downing, J. B., \& Moyer, A. M. (2012). Why parenthood, and why now? Gay men's motivations for pursuing parenthood. Family Relations, 61(1), 157-174. doi:10.1111/j.1741-3729.2011.00687.x

Gómez-Gil, E., Zubiaurre-Elorza, L., Esteva, I., Guillamon, A., Godás, T., Cruz Almaraz, M., ... Salamero, M. (2012). Hormone-treated transsexuals report less social distress, anxiety and depression. Psychoneuroendocrinology, 37(5), 662-670. doi:10.1016/j.psyneuen.2011.08.010

Gorin-Lazard, A., Baumstarck, K., Boyer, L., Maquigneau, A., Gebleux, S., Penochet, J.-C., ... Bonierbale, M. (2012). Is hormonal therapy associated with better quality of life in transsexuals? A cross-sectional study. The Journal of Sexual Medicine, 9(2), 531-541. doi:10.1111/j. 1743-6109.2011.02564.x

Gorton, R. N., \& Erickson-Schroth, L. (2017). Hormonal and surgical treatment options for transgender men (female-to-male). Psychiatric Clinics of North America, 40(1), 79-97. doi:10.1016/j.psc.2016.10.005

Hembree, W. C., Cohen-Kettenis, P. T., Gooren, L., Hannema, S. E., Meyer, W. J., Murad, M. H., ... T'Sjoen, G. G. (2017). Endocrine treatment of genderdysphoric/gender-incongruent persons: An endocrine society clinical practice guideline. The Journal of Clinical Endocrinology \& Metabolism, 102(11), 3869-3903. ), doi: 10.1210/jc.2017-01658

Jiang, D. D., Swenson, E., Mason, M., Turner, K. R., Dugi, D. D., Hedges, J. C., \& Hecht, S. L. (2019). Effects of estrogen on spermatogenesis in transgender women. Urology, (132), 117-122. doi:10.1016/j.urology.2019.06.034

Jindarak, S., Nilprapha, K., Atikankul, T., Angspatt, A., Pungrasmi, P., Iamphongsai, S., ... Tiewtranon, P. (2018). Spermatogenesis abnormalities following hormonal therapy in transwomen. BioMed Research International, 2018, 7919481. doi:10.1155/2018/7919481

Kyweluk, M. A., Sajwani, A., \& Chen, D. (2018). Freezing for the future: Transgender youth respond to medical fertility preservation. International Journal of Transgenderism, 19(4), 401. doi:10.1080/15532739.2018. 1505575

Leavy, M., Trottmann, M., Liedl, B., Reese, S., Stief, C., Freitag, B., ... Kölle, S. (2017). Effects of elevated $\beta$-estradiol levels on the functional morphology of the testis-new insights. Scientific Reports, 7(1), 39931. doi:10. 1038/srep39931

Matoso, A., Khandakar, B., Yuan, S., Wu, T., Wang, L. J., Lombardo, K. A., ... Yakirevich, E. (2018). Spectrum of findings in orchiectomy specimens of persons undergoing gender confirmation surgery. Human Pathology, (76), 91-99. doi:10.1016/j.humpath.2018.03.007 
Mattawanon, N., Spencer, J. B., Schirmer, D. A., \& Tangpricha, V. (2018). Fertility preservation options in transgender people: A review. Reviews in Endocrine and Metabolic Disorders, 19(3), 231. doi:10.1007/s11154-0189462-3

Motmans, J., de Boilley, I., \& Debunne, S. (2009). Leven als transgender in Belgie: de sociale en juridische situatie van transgender personen in kaart gebracht. Brussel: Instituut voor de gelijkheid van vrouwen en mannen.

Motmans, J., T'Sjoen, G., \& Meier, P. (2011). De levenskwaliteit van transgender personen in Vlaanderen. Antwerpen: Steunpunt Gelijkekansenbeleid.

Motmans, J., Wyverkens, E., \& Defreyne, J. (2018). Being transgender in Belgium. Ten years later. Brussels: Institute for the equality of women and men.

Murad, M. H., Elamin, M. B., Garcia, M. Z., Mullan, R. J., Murad, A., Erwin, P. J., \& Montori, V. M. (2010). Hormonal therapy and sex reassignment: A systematic review and meta-analysis of quality of life and psychosocial outcomes. Clinical Endocrinology, 72(2), 214-231. doi:10.1111/j.1365-2265.2009.03625.x

Nahata, L., Curci, M. B., \& Quinn, G. P. (2018). Exploring Fertility Preservation Intentions Among Transgender Youth. Journal of Adolescent Health, 62(2), 123-125. doi: 10.1016/j.jadohealth.2017.11.288

Nahata, L., Tishelman, A. C., Caltabellotta, N. M., \& Quinn, G. P. (2017). Low fertility preservation utilization among transgender youth. Journal of Adolescent Health, 61(1), 40-44. doi:10.1016/j.jadohealth.2016.12.012

Newfield, E., Hart, S., Dibble, S., \& Kohler, L. (2006). Female-to-male transgender quality of life. Quality of Life Research : An International Journal of Quality of Life Aspects of Treatment, Care and Rehabilitation, 15(9), 1447-1457. doi:10.1007/s11136-006-0002-3

Newport, F., \& Wilke, J. (2013). Desire for Children Still Norm in US.

O’Flaherty, M., \& Fisher, J. (2008). Sexual orientation, gender identity and international human rights law: Contextualising the Yogyakarta Principles. Human Rights Law Review, 8(2), 207-248. doi:10.1093/hrlr/ngn009

Principles, Y. (2017). The Yogyakarta Principles Plus 10: Additional Principles and State Obligations on the Application of International Human Rights Law in Relation to Sexual Orientation. Gender Identity, Gender Expression and Sex Characteristics, to Complement the Yogyakarta Principles. Geneva: International Commission of Jurists (ICJ).

Rakic, Z., Starcevic, V., Maric, J., \& Kelin, K. (1996). The outcome of sex reassignment surgery in Belgrade: 32 patients of both sexes. Archives of Sexual Behavior, 25(5), 515-525. doi:10.1007/BF02437545

Riggs, D. W., \& Bartholomaeus, C. (2018). Fertility preservation decision making amongst Australian transgender and non-binary adults. Reproductive Health, 1(15), 181. doi:10.1186/s12978-018-0627-z

Russell, A. M., Galvin, K. M., Harper, M. M., \& Clayman, M. L. (2016). A comparison of heterosexual and LGBTQ cancer survivors' outlooks on relationships, family building, possible infertility, and patient-doctor fertility risk communication. Journal of Cancer Survivorship: Research and Practice, 10(5), 935-942. doi:10.1007/s11764-0160524-9

Schneider, F., Neuhaus, N., Wistuba, J., Zitzmann, M., Heß, J., Mahler, D., ... Kliesch, S. (2015). Testicular functions and clinical characterization of patients with gender dysphoria (GD) undergoing sex reassignment surgery (SRS). The Journal of Sexual Medicine, 12(11), 2190-2200. doi: $10.1111 /$ jsm.13022

Smith, Y. L., Van Goozen, S. H., Kuiper, A., \& CohenKettenis, P. (2005). Sex reassignment: Outcomes and predictors of treatment for adolescent and adult transsexuals. Psychological Medicine, 35(1), 89-99. doi:10.1017/ S0033291704002776

T'Sjoen, G., Van Caenegem, E., \& Wierckx, K. (2013). Transgenderism and reproduction. Current Opinion in Endocrinology, Diabetes, and Obesity, 20(6), 575-579.

UNESCO. (2009). (1997). International Standard Classification of Education (ISCED). Montreal: UNESCO Institute for Statistics (UIS).

Weyers, S., Elaut, E., De Sutter, P., Gerris, J., T'Sjoen, G., Heylens, G., ... Verstraelen, H. (2009). Long-term assessment of the physical, mental, and sexual health among transsexual women. The Journal of Sexual Medicine, 6(3), 752-760. doi:10.1111/j.1743-6109.2008. 01082.x

Wierckx, K., Stuyver, I., Weyers, S., Hamada, A., Agarwal, A., De Sutter, P., \& T'Sjoen, G. (2012). Sperm freezing in transsexual women. Archives of Sexual Behavior, 41(5), 1069-1071. doi:10.1007/s10508-012-0012-x

Wierckx, K., Van Caenegem, E., Elaut, E., Dedecker, D., Van de Peer, F., Toye, K., ... T'Sjoen, G. (2011). Quality of life and sexual health after sex reassignment surgery in transsexual men. The Journal of Sexual Medicine, 8(12), 3379-3388. doi:10.1111/j.1743-6109.2011.02348.x

Wierckx, K., Van Caenegem, E., Pennings, G., Elaut, E., Dedecker, D., Van de Peer, F., ... T'Sjoen, G. (2012). Reproductive wish in transsexual men. Human Reproduction, 27(2), 483-487. doi:10.1093/humrep/der406 